\title{
USEPA LEAF methods for characterizing phosphorus and potentially toxic elements in raw and thermally treated sewage sludge
}

\author{
T.Fournie $^{a}$, C.Switzer ${ }^{b}$ \& J.I.Gerhard ${ }^{a}$ \\ ${ }^{a}$ Department of Civil and Environmental Engineering, University of Western Ontario, N6A \\ 5B9, London, ON, Canada \\ ${ }^{b}$ Department of Civil and Environmental Engineering, University of Strathclyde, G1 1XQ, \\ Glasgow, UK
}

\section{Abstract}

Biologically available phosphorus supports plant growth but can also cause environmental contamination. Sequential extraction methods, such as Hedley fractionation, are the most widely used to assess available phosphorus from solids. However, such methods exhibit numerous deficiencies. The USEPA Leaching Environmental Assessment Framework (LEAF) is a tiered system developed to evaluate releases of Potentially Toxic Elements (PTEs) from solids. This study compared the Hedley fractionation method to the LEAF pH-dependent, parallel batch tests (Method 1313) and dynamic leaching column test (Method 1314) to assess the bioavailability of phosphorus. The three methods were applied to wastewater treatment plant sludge before and after thermal treatment. Both methods revealed similar qualitative trends, namely that thermal treatment transformed phosphorus into less immediately available forms. However, the Hedley and LEAF methods were inconsistent in the forms and amounts of available phosphorus recovered from the solids. The Hedley method left $40 \%$ of phosphorus unextracted from sludge and $20 \%$ from ash, suggesting that it may be less appropriate for organic materials. Moreover, only 2 of the 6 Hedley phosphorus pools were within environmentally relevant $\mathrm{pH}$ conditions. Furthermore, 
25 the Hedley method overpredicted the readily available phosphorus. In contrast, the LEAF methods 26 allowed for a more detailed analysis of phosphorus availability - while simultaneously assessing PTEs -

27 across a controlled $\mathrm{pH}$ range. Moreover, LEAF used simpler procedures and provided more easily 28 interpreted results. Thus, LEAF facilitates more robust and valuable assessment of organic and inorganic 29 solids being considered for land application.

30

31

32 


\section{Introduction}

Land application of solids, such as manure, inorganic fertilizers, and wastewater treatment plant (WWTPs) sludge, are valuable sources of phosphorus and other nutrients. However, accumulation of phosphorus within soils can increase leaching (1) as previously studied with applied manures $(2,3)$ and inorganic

37 fertilizers $(1,4)$. Released phosphorus is transported through the subsurface or via runoff to surface waters (5); contributing to eventual eutrophication (6). Determining the biologically available (i.e., bioavailable) phosphorus in land applied solids is important for developing application guidelines, maximizing beneficial use, and establishing regulatory compliance.

41 Numerous methods have been developed to quantify phosphorus, especially bioavailable phosphorus, in

42 a wide range of solids. Most literature and analytical methods focus on soils and the Hedley sequential

43 fractionation method (7) dominates the field (8-10). Hedley uses progressively stronger chemical 44 extractants to recover increasingly recalcitrant forms of phosphorus (11), inferring potential sources and 45 sinks of phosphorus based on phosphorus quantity within various fractions. Bioavailable phosphorus is 46 typically divided into several "pools" ranging from highly available to unavailable (12).

47 Hedley forms the basis for many related sequential fractionation methods (13-16). Common 48 modifications to the Hedley method include (i) an initial deionized water step prior to anion exchange resin (15), (ii) excluding quantification of microbial phosphorus (16), (iii) eliminating sonication during the extraction of moderately-bound phosphorus (13), and (iv) using heated digestion to quantify residual

51 (unavailable) phosphorus (14). Sequential phosphorus fractionation methods vary significantly in the type

52 of chemical extractant and molarity used to quantify each pool (a summary of published methods can be

53 found in Appendix A of the Supplementary Materials). Since phosphorus dissolution is highly $\mathrm{pH}$ 54 dependent (17), extraction methods are likely to yield different results for available phosphorus 55 depending on chosen extractants and procedure order $(18,19)$. Furthermore, strong extractants can 
change the chemical structure of phosphorus species (20-23). As a consequence, conclusions on

57 phosphorus availability from studies using fractionation methods are inconsistent $(18,24)$ and sometimes contradictory (25).

Studies assessing phosphorus availability in other solids including animal manure and sewage sludge have used modified versions of Hedley and soil phosphorus test procedures $(15,26-29)$. Only a few studies have

61 attempted to fractionate phosphorus in sewage sludge $(15,27,30,31)$. Such evaluations are anticipated to

62 suffer from the same problems identified for sequential fractionation of phosphorus in soils.

63 Following decades of development, the USEPA released the Leaching Environmental Assessment

64 Framework (LEAF) in 2010. LEAF is a characterization-based leaching framework combining experimental

65 data on relevant intrinsic leaching behaviour with scenario-specific information for environmental

66 assessments (32). USEPA Method 1313 from LEAF consists of a series of parallel batch experiments to

67 produce a liquid-solid partitioning curve of the material of interest as a function of $\mathrm{pH}(33)$. The complementary USEPA Method 1314 involves a column percolation experiment to obtain eluate 69 concentrations and/or cumulative release as a function of the liquid-to-solids ratio (34). LEAF has been used to assess leaching behaviour of potentially toxic elements (PTEs) from coal fly ash (e.g., 33);

71 municipal solid waste (MSW) incinerator ash (e.g., 34); concrete waste (37); and sewage sludge compost

72 (38). Using LEAF to assess phosphorus is less common and has been used for inorganic phosphorus from

73 mining waste $(39,40)$. The methodology seems promising to evaluate bioavailable phosphorus for a wide 74 range of organic/inorganic matrices.

75 The aim of this research was to evaluate analytical procedures for assessing bioavailable phosphorus from sewage sludge before and after thermal treatment. The two procedures chosen for comparison were the

77 widely used Hedley fractionation method and USEPA LEAF. This study demonstrates that the LEAF 78 provides a more consistent method for analyzing phosphorus bioavailability in sludges and suggests that 
79 it may be more widely applicable to soils and other solids under consideration for land application. This

80 study also illustrates how the LEAF methods provide valuable quantification of PTEs that may be present

81 in these materials with no further analytical steps required.

\section{Materials and Methods}

83 The sludge utilized in this study was collected from Greenway Wastewater Treatment Plant (Greenway),

84 London, Ontario, Canada. At Greenway, sludge is produced as a by-product of primary and secondary

85 treatment. Primary clarification removes settleable solids (i.e., primary sludge). Following aerobic

86 digestion and thickening, secondary clarification settles out waste activated sludge via dissolved air

87 flotation units and rotating drums. Centrifugation with polymer addition is used to dewater a combined

88 slurry of primary and waste activated sludge to produce a cake sludge. All sludge was collected as cake

89 sludge in a single batch on July $26^{\text {th }}, 2018$, to minimize compositional variability.

\subsection{Sample Preparation and Storage}

91 Sludge was oven-dried to prevent decomposition and moulding. Prior to subsequent analyses, the oven-

92 dried sludge was pulverized into a homogenous powder using an immersion blender and mortar and

93 pestle. Batches of $100 \mathrm{~g}$ of dried sludge were placed in large crucibles and heated in a muffle furnace at

$94950^{\circ} \mathrm{C}$ for 2 hours to produce incinerated sewage sludge ash (herein referred to as ash). The ash appeared

95 to be a relatively homogenous powder; no further grinding was done. All materials were stored in sealed $96 \quad 20 \mathrm{~L}$ pails at $5^{\circ} \mathrm{C}$ prior to use.

\section{2.2. Preliminary Analysis}

98 Moisture content, volatile matter, ash content, and fixed carbon of the sludge were determined following EPA Method 1684 (41), with three replicates analyzed for each. The sludge had an average moisture content of $73 \pm 0.2 \%$, volatile matter content of $18 \pm 0.3 \%$, ash content of $7 \pm 0.1 \%$, and fixed carbon 
101 content of $2 \pm 0.4 \%$, all on a wet-mass basis. Laboratory incineration at $950^{\circ} \mathrm{C}$ resulted in mass loss of $102 \sim 93 \%$.

103 Pseudo-total elemental concentrations (herein referred to as total concentrations) were determined for 104 aluminum, cadmium, cobalt, chromium, copper, iron, manganese, molybdenum, nickel, phosphorus, lead, 105 and zinc within sludge and ash. Elements were extracted from the solid phase through microwave assisted 106 acid digestion following USEPA Method 3051A (42). Acid digestions were performed in triplicate.

\subsection{Hedley Method}

In the Hedley method, inorganic and organic phosphorus fractions are extracted using progressively 109 stronger chemical reagents. Figure 1a illustrates the series of 6 extracts $(\mathrm{H} 1-\mathrm{H} 6)$. In each extraction, $1 \mathrm{~g}$ dried sample was added to a $250 \mathrm{~mL}$ polyethylene bottle. An anion exchange resin bag (Dowex ${ }^{\mathrm{TM}}$ resin,

111 Sigma-Aldrich Canada Co., within $41 \mu \mathrm{m}$ nylon mesh, Fisher Scientific Co Ltd.) and $30 \mathrm{~mL}$ deionized water 112 were added and shaken at 170 RPM on a rotary shaker for 16 hours. Phosphorus was removed from the 113 resin with $20 \mathrm{~mL} 0.5 \mathrm{M}$ hydrochloric acid $(\mathrm{HCl})(\mathrm{H} 1)$. The supernatant was decanted and disposed of 114 followed by the addition of $30 \mathrm{~mL} 0.5 \mathrm{M}$ sodium bicarbonate $\left(\mathrm{NaHCO}_{3}\right)$. The bottle was shaken for 16 115 hours, then the supernatant was collected $(\mathrm{H} 2)$. This process was repeated, adding $30 \mathrm{~mL} 0.1 \mathrm{M}$ sodium 116 hydroxide $(\mathrm{NaOH})(\mathrm{H} 3), 20 \mathrm{~mL} 0.1 \mathrm{M} \mathrm{NaOH}$ with 2 min sonication (H4), and $30 \mathrm{~mL} 1 \mathrm{M} \mathrm{HCl}(\mathrm{H} 5)$. Following 117 the resin extraction procedure, a repeat sample was used to determine the microbial biomass phosphorus 118 by spiking the solid material with $1 \mathrm{~mL}$ concentrated chloroform $\left(\mathrm{CHCl}_{3}\right)$, leaving the sample to fumigate 119 for 16 hours, then extracting the phosphorus with $30 \mathrm{~mL} 0.5 \mathrm{M} \mathrm{NaHCO}_{3}$. The microbial biomass 120 phosphorus is calculated as the difference between the total labile phosphorus extracted with only $121 \mathrm{NaHCO}_{3}$ and pretreated with $\mathrm{CHCl}_{3}(43)$. The residual phosphorus is determined by digesting (H5) in $10 \mathrm{M}$ 122 sulfuric acid $\left(\mathrm{H}_{2} \mathrm{SO}_{4}\right)(\mathrm{H} 6)$. Importantly, $\mathrm{pH}$ is not dictated in this method. Instead, following each 123 procedure step, eluate samples were analyzed for $\mathrm{pH}$ and conductivity using a Fisher Scientific accumet ${ }^{\mathrm{TM}}$ 
$124 \mathrm{AB} 200 \mathrm{pH} / \mathrm{mV} /$ Conductivity meter (Waltham, MA, USA), then preserved for further analysis of inorganic

125 and total phosphorus. Concentrations of organic phosphorus were calculated as the difference between

126 total and inorganic phosphorus in each extract. All extractions were performed in triplicate with results

127 presented as averages including standard error.

128 Each extract is associated with a phosphorus pool and mechanism of phosphorus binding to solid surfaces,

129 as illustrated in Figure 1a. Whether each of the chemical extractants can accurately dissociate the target 130 phosphorus compounds from the solids is not fully understood, and it is likely that each pool contains a 131 combination of compounds (44).

USEPA LEAF Method 1313 consists of 9 parallel batch extractions (Figure 1b) to produce a liquid-solid partitioning curve of the material of interest over eluate $\mathrm{pH}$ range $2 \leq \mathrm{pH} \leq 13$. For each extraction, $10 \mathrm{~g}$ of material was combined with $100 \mathrm{~mL}$ of extraction solution consisting of deionized water with either $2 \mathrm{~N}$ nitric acid $\left(\mathrm{HNO}_{3}\right)$ or $1 \mathrm{~N}$ potassium hydroxide $(\mathrm{KOH})$ to achieve 9 target $\mathrm{pH}$ values \pm 0.5 for each (Figure 1b). The liquid-to-solids ratio was $10 \mathrm{~mL} / \mathrm{g}$-dry. Quantities of $\mathrm{HNO}_{3}$ or $\mathrm{KOH}$ were determined after measuring the native $\mathrm{pH}$ of the material using deionized water. Mixtures were prepared in $125 \mathrm{~mL}$ HDPE 139 bottles, sealed, and shaken end-over-end at 170 RPM for 24 hours. Following shaking, bottles were centrifuged. $\mathrm{pH}$ was measured to confirm the final solution remained within target ranges; electrical

141 conductivity was also measured. Eluate samples were filtered, preserved, and analyzed for total and 142 inorganic phosphorus. Additionally, cadmium, cobalt, chromium, copper, molybdenum, nickel, lead, and 143 zinc were analyzed because they are typically monitored and/or regulated at WWTPs.

144 USEPA LEAF Method 1314 uses a percolation column experiment to evaluate constituent release from the material of interest as a function of the liquid-to-solid ratio $(L / S)$. The $L / S$ is computed as the quantity of 146 solution $(\mathrm{mL})$ passed through the fixed quantity of solid material $(\mathrm{g})$ within the column. A glass column 
147 (DWK Life Sciences, KIMBLE ${ }^{\circledR}$ ) of $5 \mathrm{~cm}$ outer diameter and $30 \mathrm{~cm}$ height was used for each test. A $5 \mathrm{~cm}$

148 layer of acid-washed, air-dried sand (Number 12, Bell \& Mackenzie) was packed into the base of the 149 column. Dried material (sludge or ash) was added to the column in successive layers ( $60 \mathrm{~g})$, tamping each 150 using a glass rod, until $300 \mathrm{~g}$ of sample was added. A second $5 \mathrm{~cm}$ layer of acid-washed sand was added 151 to the top of the material pack to minimize material loss from the column. Deionized water (neutral $\mathrm{pH}$ ) 152 was pumped using a Masterflex ${ }^{\circledR} \mathrm{L} / \mathrm{S}^{\circledR}$ digital peristaltic pump (Cole-Parmer Instrument Company, IL, USA) 153 upwards at a L/S of $1.0 \mathrm{~mL} / \mathrm{g} /$ day until breakthrough occurred. The pump was stopped, letting the 154 saturated column rest for 24 hours. After resting, water flow was reintroduced and maintained at rate of $1550.75 \pm 0.5 \mathrm{~mL} / \mathrm{g} /$ day to collect the nine eluate samples (T01-T09) at specified L/S of 0.2, 0.5, $1.0 \pm 0.1$, and $1561.5,2.0,4.5,5.0,9.5$, and $10.0 \pm 0.2 \mathrm{~mL} / \mathrm{g}$-dry matter. The $\mathrm{pH}$ and electrical conductivity of each eluate 157 sample were measured within an hour of collection. Eluate samples were filtered through $0.45 \mu \mathrm{m}$ filters 158 (Whatman $0.45 \mu \mathrm{m}$ celluacetate filters, VWR International) via a vacuum pump. Filtered samples were 159 preserved with concentrated $\mathrm{HNO}_{3}$ and analyzed for total and inorganic phosphorus as well as cadmium, 160 cobalt, chromium, copper, molybdenum, nickel, lead, and zinc.

\subsection{Analytical Methods}

162 Total elemental concentrations in the microwave extracts, Hedley method extracts, and LEAF Method 1631313 and 1314 samples, were analyzed using an Agilent 720 Inductive Coupled Plasma Optical Emission 164 Spectrometer (ICP-OES) following USEPA Method 6010D (45).

165 Total phosphorus in the Hedley method extracts and USEPA method 1313 and 1314 samples was 166 measured using ICP-OES to avoid interferences that affect colorimetric analysis (46). Inorganic phosphorus 167 was measured as dissolved orthophosphate $\left(\mathrm{PO}_{4}{ }^{3-}\right)$ by High-Performance Liquid Chromatography (HPLC) 168 using direct injection by a Water ${ }^{\circledR} 515$ pump following USEPA Method 300 (47). 
169 All extracts were run at dilution factors of 1:1-1:100 (1:10-1:100 for digested samples) on both ICP-OES

170 and HPLC to ensure all elements were within detection ranges for every sample. Triplicates, method

171 blanks, and spiked extracts were also run on both ICP-OES and HPLC to ensure quality assurance and

172 quality control.

173 Due to differences in the sludge versus post-treatment ash, all results were normalized in terms of the 174 starting material: mass of element per mass of initial dry sludge (mg/kg-DS). Results in terms of dry matter 175 (i.e., $\mathrm{mg} / \mathrm{kg}-\mathrm{dm}$ ) can be found in Supplementary Materials (Appendix C). 


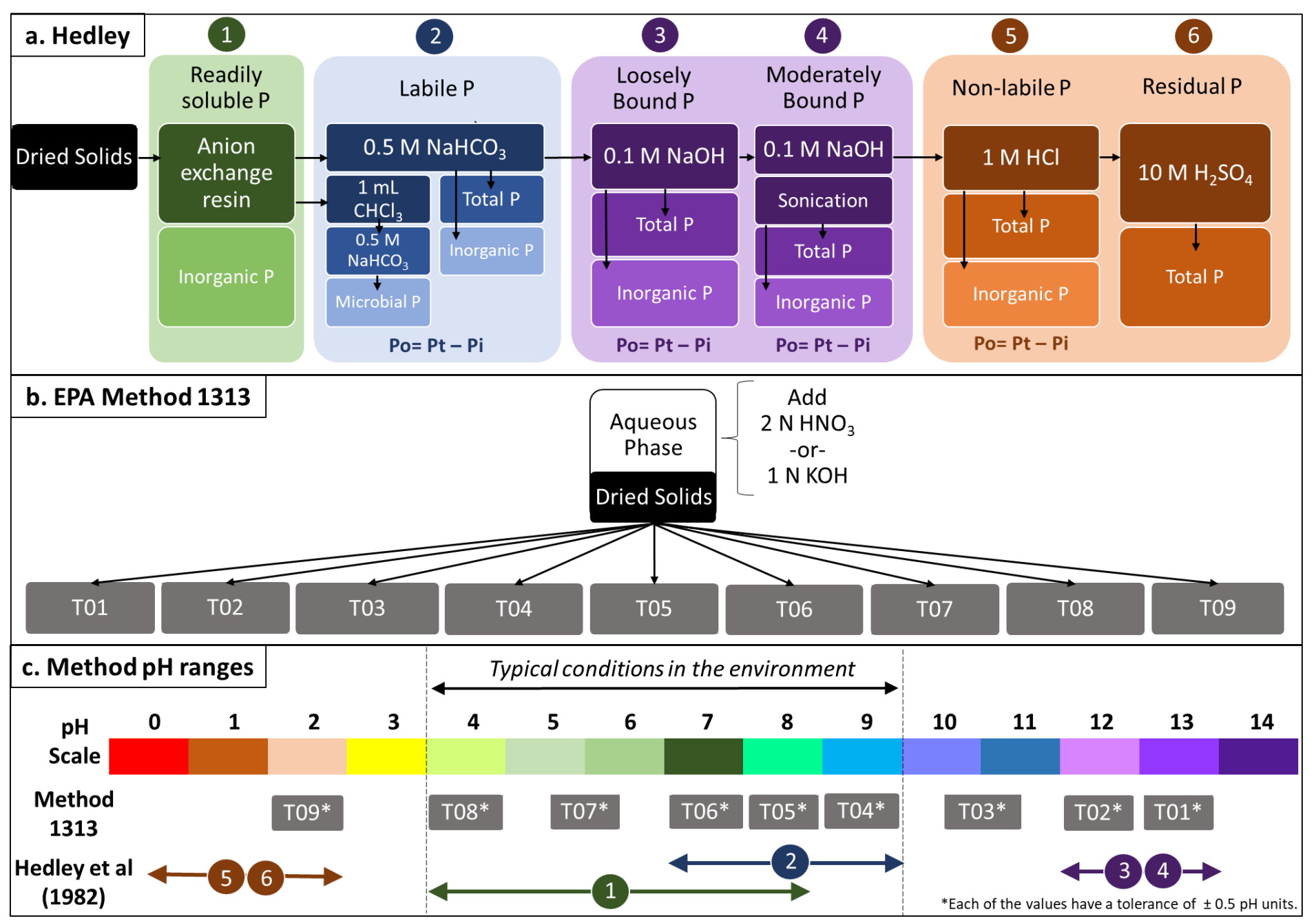

Figure 1: procedural schematics for $a$. the Hedley et al. (1982) fractionation procedure and b. USEPA Method 1313 parallel batch extraction. The 6 steps of the Hedley procedure (H1-H6) are outlined in a., including the chemical extractant and molarity used for to quantify each phosphorus pool. The phosphorus pools are assumed to decrease in plant availability from step (H1) being immediately available to step (H6) being unavailable. H1 is associated with readily soluble inorganic phosphorus (14). H2 is correlated to labile inorganic phosphorus from P-esters bound to surfaces of aluminum and iron (9). H3 and $\mathrm{H} 4$ are moderately-labile phosphorus pools assumed to contain phosphorus chemisorbed

181 to amorphous and some crystalline aluminum and iron oxides/hydroxides (13). H5 is assumed to be non-labile phosphorus bound to calcium-species (9). The pH ranges corresponding
182 to Hedley method pools and USEPA Method 1313 samples are provided in c. and compared to typical environmental pH conditions. 


\section{Results and Discussion}

\subsection{Phosphorus Analysis}

\subsubsection{Hedley Method}

Figure 2 presents Hedley method results for sludge and ash. In the immediately soluble phosphorus pool

187 (H1), $1100 \mathrm{mg} / \mathrm{kg}$ - dry sludge (i.e., $\mathrm{mg} / \mathrm{kg}-\mathrm{DS}$ ) was extracted from both sludge and ash, comprising 2 and

$1885 \%$ of total phosphorus, respectively. Majority was from unavailable pools ( $\mathrm{H} 3-\mathrm{H} 6)$ : $57 \%$ and $79 \%$ for

189 sludge and ash, respectively. The fraction of total phosphorus released from non-labile (H5) and residual

190 (H6) pools increases from $32 \%$ in sludge to $62 \%$ in ash. Thermal treatment seems to have transformed a

191 fraction of phosphorus to less available forms.

192 Hedley assumes organic phosphorus is the difference between total and inorganic phosphorus. The sludge 193 seems to have larger proportions of organic phosphorus compared to the ash. Phosphorus in the sludge 194 extracted by Hedley consists of $32 \%$ organic phosphorus distributed as $54 \%$ labile (H2), $16 \%$ loosely bound $195(\mathrm{H} 3), 10 \%$ moderately bound $(\mathrm{H} 4)$, and $85 \%$ non-labile (H5). In contrast, only $10 \%$ of phosphorus in the 196 ash is present as organic, distributed as $14 \%$ labile $(\mathrm{H} 2),<1 \%$ loosely bound $(\mathrm{H} 3), 10 \%$ moderately bound $197(\mathrm{H} 4)$, and $<1 \%$ non-labile $(\mathrm{H} 5)$. This reduction in organic phosphorus during thermal treatment is also 198 evident when comparing microbial phosphorus: $310 \mathrm{mg} / \mathrm{kg}-\mathrm{DS}$ of microbial phosphorus for sludge 199 versus negligible for ash. This is due to the destruction of any microbial biomass present in the sludge 200 which would cause subsequent release of any microbially-bound phosphorus.

201 Phosphorus recovered from all steps of Hedley accounted for only $60 \%$ of total phosphorus extracted by 202 microwave digestion from sludge and $80 \%$ from ash (Figure 2). This is consistent with unextracted 203 phosphorus of $20-70 \%$ in other studies $(13,48)$. Hedley was developed for use in soils that have 

compare the relative changes to functional phosphorus pools between samples.

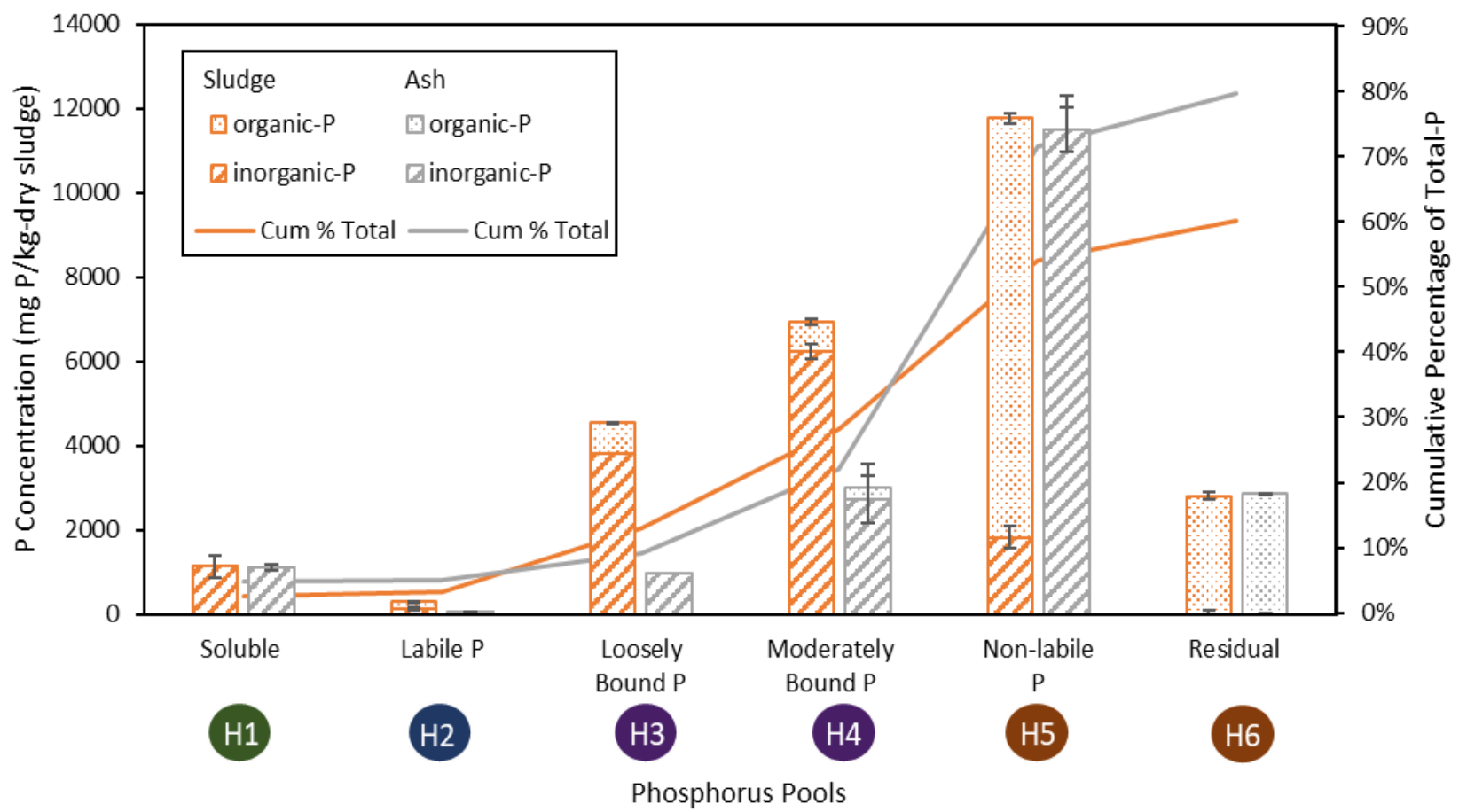

Figure 2: Results from the Hedley method on sludge and ash presented in orange and gray, respectively. The different P-pools are shown on the $x$-axis and labelled with numbers corresponding to the respective extraction steps shown in the Hedley procedural schematic (Figure 1a.). The full bar represents the total- $P$ in that fraction. The bars are subdivided into inorganic-and organic- $P$ which are shown with diagonal stripes and dots, respectively. The $P$ concentration is given in $m g$ of $P$ per $k g$ of dry sludge. The cumulative percentage of $P$ extracted by the Hedley method compared to the total-P for the sludge and ash are plotted as lines on the secondary axis.

\subsubsection{USEPA Method 1313}

USEPA Method 1313 was used to quantify pH-dependent phosphorus availability (Figure 3). Sludge is slightly acidic while ash is slightly alkaline with native $\mathrm{pH}$ of 5.8 and 8.0 , respectively. At native pHs, phosphorus availabilities were at a minimum from both sludge and ash; increasing significantly under

211 strongly acidic and alkaline conditions.

$212 \mathrm{At} \mathrm{pH}<7$, phosphorus availability was greater in ash than sludge, whereas at $\mathrm{pH}>7$, the opposite was

213 true. Under acidic conditions $(\mathrm{pH}<6)$, the concentration of total available phosphorus in ash increased from 370 to $3800 \mathrm{mg} / \mathrm{kg}$-DS and from 150 to $1300 \mathrm{mg} / \mathrm{kg}$-DS in sludge under the same conditions. Organic 
215 phosphorus accounts for an important fraction of available phosphorus in both materials in these 216 conditions: $15-80 \%$ in sludge and $17-83 \%$ in ash. Most of the available organic phosphorus in ash 217 becomes available at $\mathrm{pH}=4$, whereas, in sludge, available organic phosphorus varies more with $\mathrm{pH}$. This 218 difference likely reflects the absence of organic matter in ash.

219 Above $\mathrm{pH} 7$, the concentration of available phosphorus in sludge increases almost linearly with increasing $220 \mathrm{pH}$. In slightly alkaline conditions $(7.5 \leq \mathrm{pH} \leq 9.5)$, available phosphorus from ash was $0.4 \%$ of available 221 phosphorus from sludge. As alkalinity increased $(\mathrm{pH}>9.5)$, available phosphorus increased linearly in both 222 sludge and ash. Available phosphorus in ash remained $20-40 \%$ of that available in sludge $(3100-17,000$ $223 \mathrm{mg} / \mathrm{kg}-\mathrm{DS}$ and $650-6400 \mathrm{mg} / \mathrm{kg}-\mathrm{DS}$ in sludge and ash, respectively). Organic phosphorus accounts for a 224 significantly larger fraction of available phosphorus in sludge than ash in alkaline conditions: $29-68 \%$ 225 versus $0-61 \%$.

226 In summary, sludge shows generally higher concentrations of immediately available phosphorus across 227 environmentally relevant $\mathrm{pH}$ conditions $(3.5<\mathrm{pH}<8.5)$ while ash contains higher available phosphorus 228 under increasingly acidic conditions $(\mathrm{pH} \leq 4)$. Thermal treatment of sludge is likely transforming a portion 229 of immediately available phosphorus at native $\mathrm{pH}$ into more recalcitrant forms (27). This transformation 230 may have important benefits since, after land application, immediately available phosphorus may be 231 flushed rapidly from the system causing eutrophication of nearby surface waters. Conducting dynamic 232 leaching tests (Method 1314) allows this potential impact to be directly studied. 


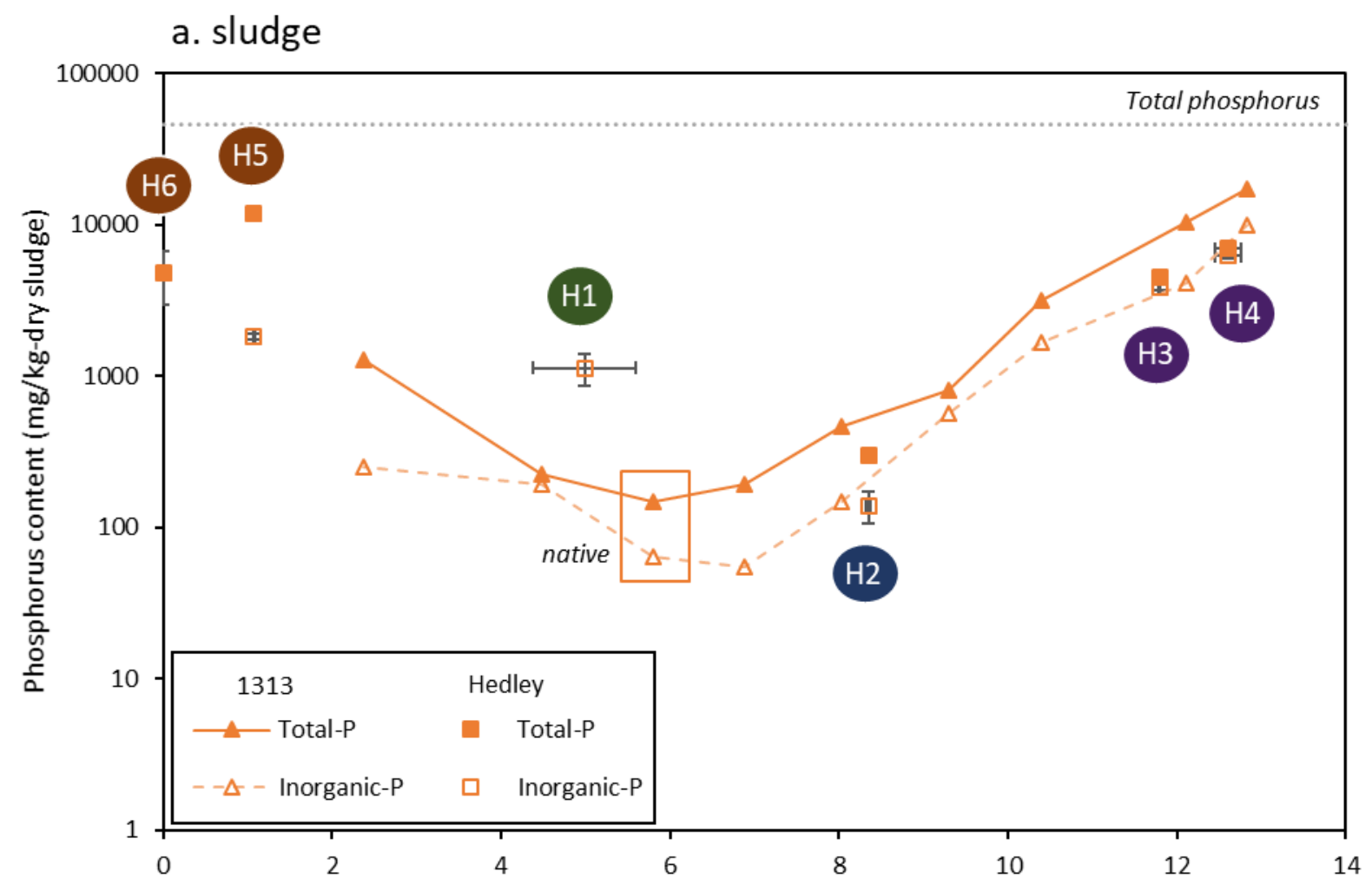

b. ash

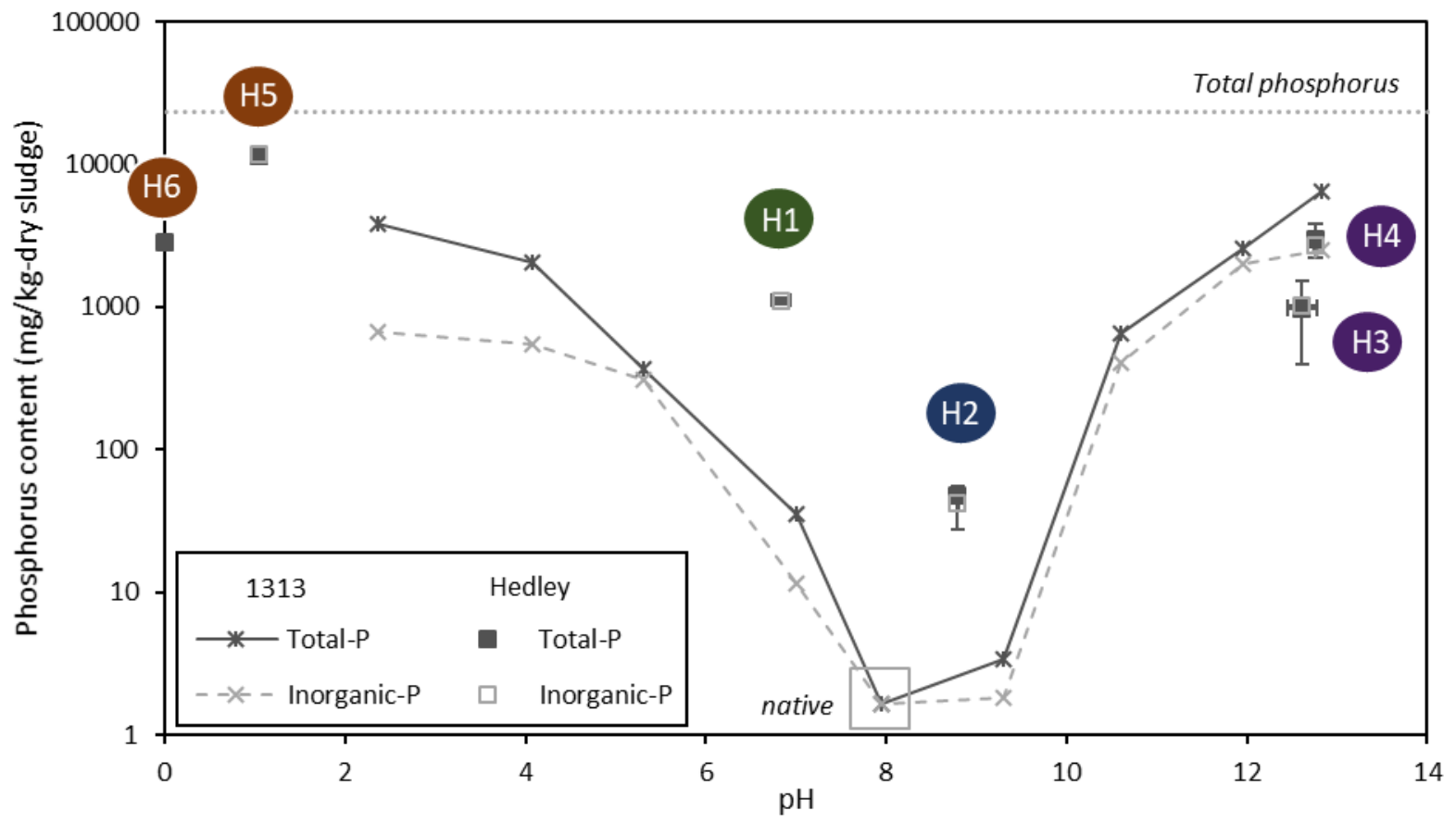

Figure 3: Comparison of the available-P as a function of $\mathrm{pH}$ for a. sludge and $b$. ash using the results of the EPA leaching method 1313 and the Hedley fractionation procedure. Method 1313 results are plotted along the curves while the Hedley results are plotted as discrete points using square markers. The extraction steps corresponding to each of the points are labelled as 1-6 (see Figure 1 for the full procedure). Total phosphorus is presented as the dotted line. The native $p H$ of each material is outlined in a box. 
USEPA Method 1314 dynamic leaching tests evaluate constituent release from materials as a function of

241 increasing L/S ratio. The highest concentration of phosphorus is released immediately from both sludge

242 and ash (Figure 4); however, important differences were observed between their release profiles.

243 In sludge, an initial slug of $9.5 \mathrm{mg} / \mathrm{kg}-\mathrm{DS}$ of phosphorus was released ( $\mathrm{L} / \mathrm{S}=0.2$ ) followed by diminishing

244 rates. Phosphorus rapidly becomes availability - limited as minimal release occurs with additional

245 percolation $(0.5 \leq \mathrm{L} / \mathrm{S} \leq 10)$, leading to a cumulative release of $19.7 \mathrm{mg} / \mathrm{kg}-\mathrm{DS}$. Of the total eluted 246 phosphorus, $48 \%$ is released immediately. This behaviour is consistent with applications of sludge to soil

247 where a rapid initial release of phosphorus, which can be linked to eutrophication (5).

248 In ash, the initial slug of phosphorus leached was smaller - 92\% less than in sludge - and released more 249 slowly $(0.8 \mathrm{mg} / \mathrm{kg}-\mathrm{DS}$ over $0.2 \leq \mathrm{L} / \mathrm{S} \leq 2.0)$. Organic phosphorus accounted for $37 \%$ of this initial slug as 250 compared to $95 \%$ of the initial slug in sludge. Total and inorganic phosphorus then exhibited a continued 251 slow release for the remainder of the ash experiment $(2.0 \leq \mathrm{L} / \mathrm{S} \leq 10)$, exhibiting solubility-limited 252 behaviour. Importantly, approximately $81 \%$ of total eluted phosphorus from ash was in the inorganic 253 form, compared to $52 \%$ from sludge.

254 Early washout of soluble ions did not have a substantial impact on eluate $\mathrm{pH}$ in either material, although 255 thermal treatment affected the initial $\mathrm{pH}$ (Figure 4). The elevated temperatures of incineration are 256 associated with processes such as denaturation of organic acids and combustion of organic materials that 257 have been observed to cause similar increases in soil pH (49). Combustion of organic matter within sludge 258 resulted in about $50 \%$ of phosphorus being released through volatilization (see Supplementary Materials 259 Appendix A), illustrating an important mechanism for recovery during thermal treatment. Most of what 260 remained within the ash was likely transformed into more crystalline forms (50). The net result was a 261 decrease in immediate phosphorus leaching, agreeing with the Method 1313 results at native $\mathrm{pH}$. 


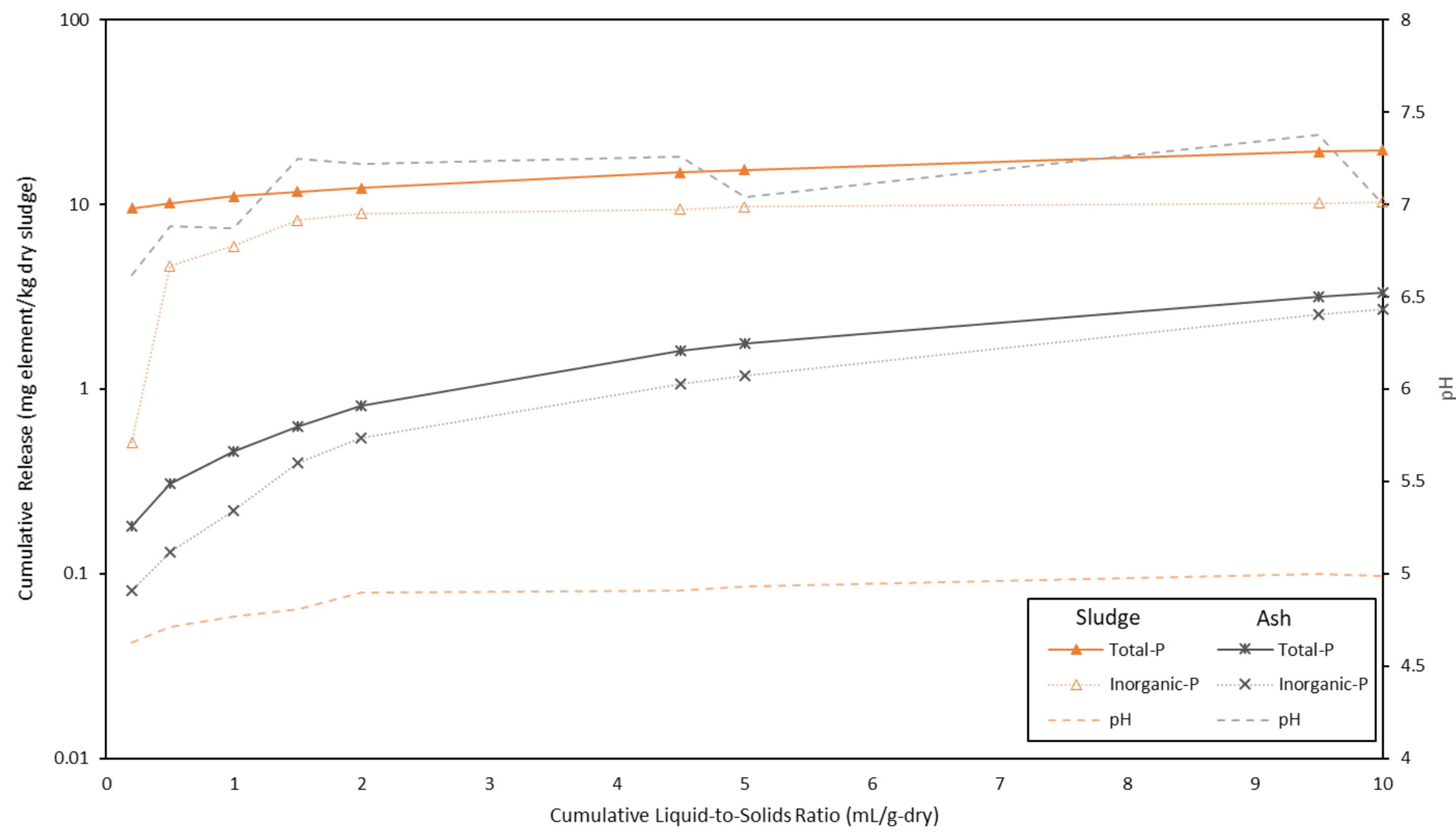

Figure 4: The USEPA method 1314 column percolation experiments for sludge (orange) and ash (grey). The concentrations of released phosphorus are shown in mg of phosphorus per $\mathrm{kg}$ dry sludge. The darker solid lines and lighter broken lines show total-and inorganic-P release, respectively. The pH changes over the column leaching experiment are plotted as dotted lines on the secondary $y$-axis. 


\subsection{Potentially Toxic Element Availability and Leaching}

268 One of the barriers to land application of sludge, with or without further treatment, is potential release

269 of PTEs. LEAF Methods 1313 and 1314 provide additional data to evaluate their potential release. Figure

2705 shows Method 1313 plots of 8 elements of concern identified in Ontario Regulation 338/09 (O. Reg. 338

271 CM1 NASM) from the Nutrient Management Act (2002) (see Supplementary Materials for PTE results from

272 Method 1314).

273 All elements generally had higher availabilities from sludge compared to ash. The exceptions typically

274 occurred in limited circumstances not relevant to conditions for land application $(\mathrm{pH}=4)$. Cadmium,

275 molybdenum, and lead all had similar availabilities from sludge and ash under neutral to acidic conditions

276 and higher availabilities from sludge than ash under alkaline conditions. To understand how availability

277 translates to potential release behaviour upon potential land application, results from Methods 1313 and

2781314 must be viewed together.

279 Cumulative releases of all elements apart from molybdenum were higher from sludge than ash, often

280 significantly higher (see Figure C2, Supplementary Materials). Importantly, although lead had higher

281 available concentration at neutral pH (Figure 5), lead release from ash was small and $5 \%$ of lead released

282 from sludge (Figure C2, Supplementary Materials). Among the other 6 PTEs, similar release trends were

283 observed; cumulative releases from ash were $<1-10 \%$ of the cumulative releases from sludge, usually

284 because of a relatively large initial slug released from the sludge. The thermal treatment process appears

285 to affect the availability and leaching of PTEs in the resulting material, similar to phosphorus. 

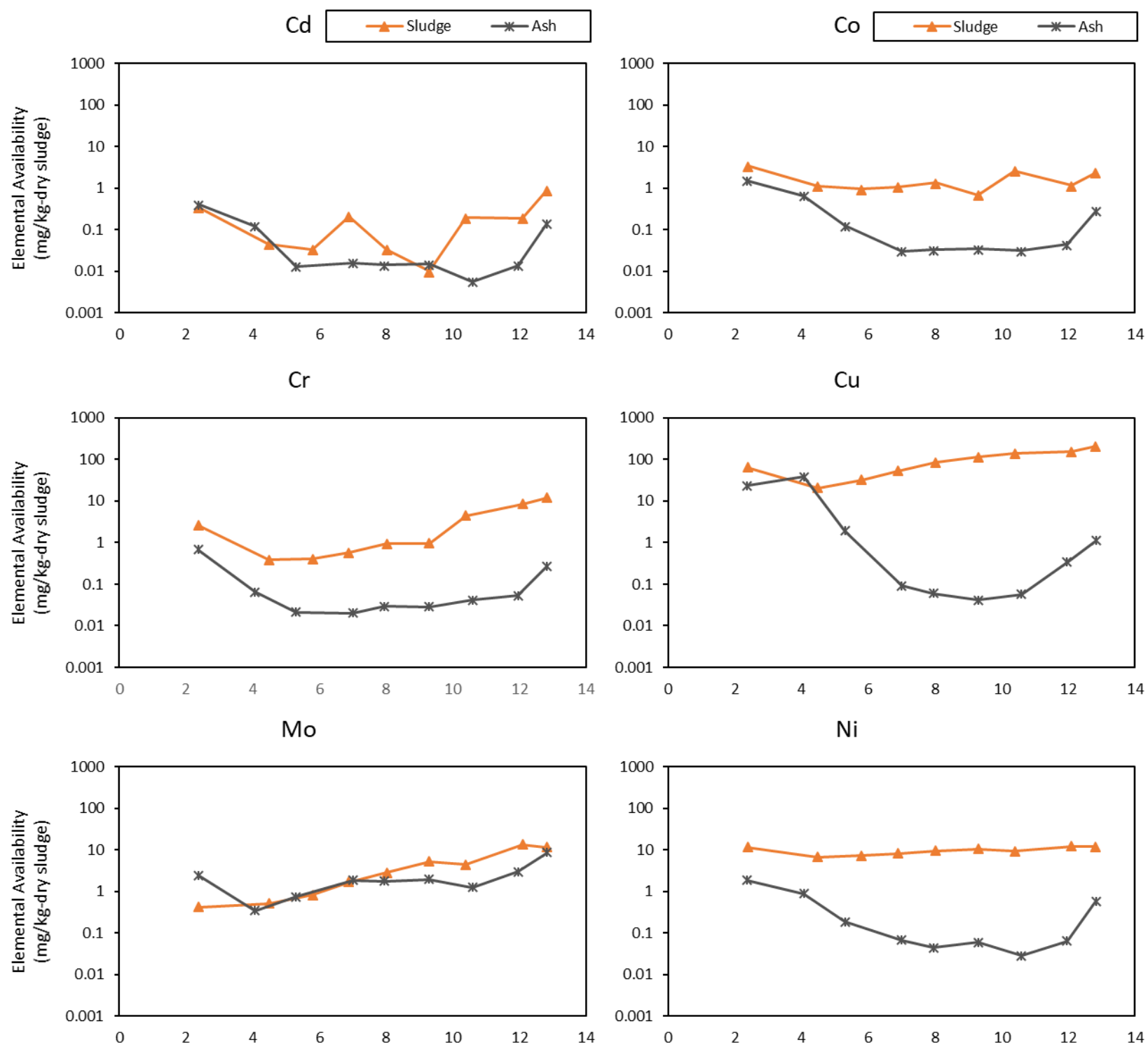

$\mathrm{Ni}$

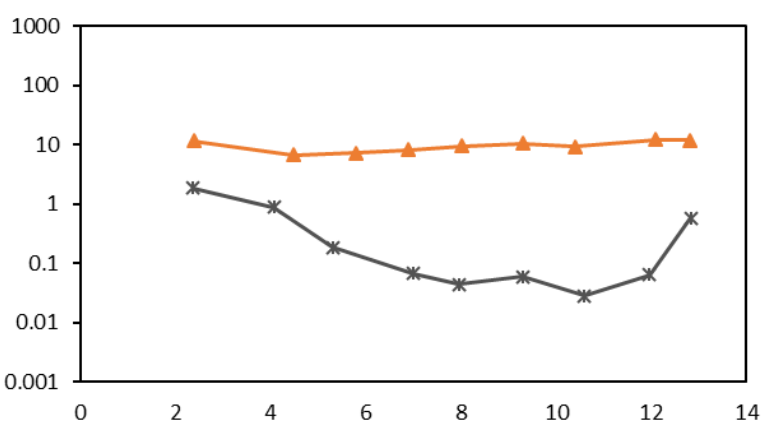

$\mathrm{Pb}$

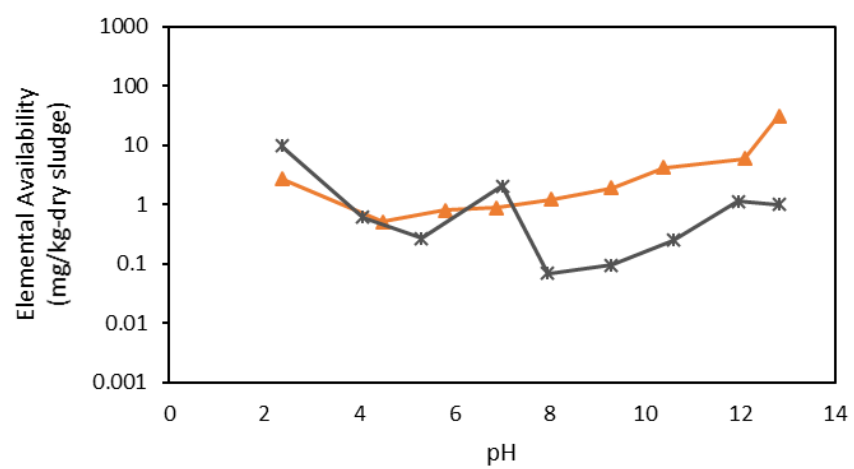

$\mathrm{Zn}$

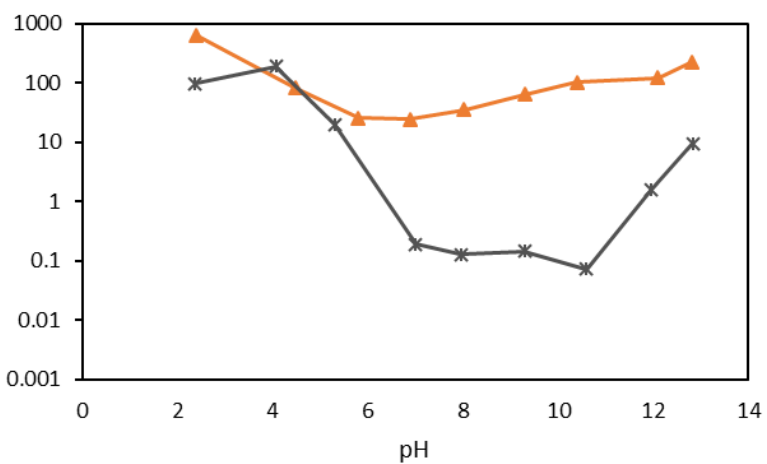

Figure 5: pH-dependent leaching curves for 8 PTEs of concern from O. Reg. 338 CM1 NASM for both sludge and ash, following 290 USEPA Method 1313. Values have been normalized per $\mathrm{kg}$ dry sludge. 


\subsection{Discussion: Comparing Hedley and LEAF Methods}

292 LEAF methods are easier to execute than sequential fractionation procedures. Hedley uses 6 different 293 chemical extractants of varying molarities while Method 1313 requires only 2 and Method 1314 only 1 294 (deionized water). Method 1313 consists of 9 parallel batch extractions that are performed 295 simultaneously, yielding independent results. Although Method 1314 is technically also a series extraction 296 from the percolation column, compared to sequential fractionation the sample collection is simplistic. 297 Sample quantity may also influence results. Hedley indicates $1 \mathrm{~g}$ dried sample which may not fully represent material characteristics. Method 1313 utilizes $10 \mathrm{~g}$ (or more) dried sample for each extraction and Method 1314 uses at least $300 \mathrm{~g}$ dried sample in the column. Although likely more characteristic, the larger sample sizes used in LEAF may also be a drawback compared to Hedley if sample amount is limited.

Quantifying release of phosphorus from each material is important to evaluate what plants may receive. Inconsistencies between Hedley and LEAF methods have important implications. Hedley soluble (H1) and labile (H2) pools typically correspond to points between T04 and T08 in Method 1313 (Figure 1c). In this work, soluble $(\mathrm{H} 1)$ and labile $(\mathrm{H} 2)$ pools correspond to $\mathrm{TO7}(\mathrm{pH}=5.5)$ and $\mathrm{TO5}(\mathrm{pH}=8)$, respectively, in the sludge and to T06 $(\mathrm{pH}=7)$ and T04 $(\mathrm{pH}=9)$, respectively, in the ash (Figure 1c). Phosphorus released at native $\mathrm{pH}$ in Method 1313 is inconsistent with soluble $(\mathrm{H} 1)$ pool from Hedley, releasing $6 \%$ and $<1 \%$

307 from the sludge and ash, respectively (Figure 3). Furthermore, in sludge, soluble (H1) pool exceeds 308 available phosphorus determined by Method 1313 at $3.5<\mathrm{pH}<9.5$ (i.e., samples T04 - T08) making it 309 only comparable at pH extremes, which is not relevant to land application. Similarly, in ash, soluble (H1) 310 pool only matches the magnitude of available phosphorus from Method 1313 determined in more 311 extreme conditions $(\mathrm{pH}<5$ or $\mathrm{pH}>11)$. Additional discrepancies arise considering Method 1314 results. 312 Cumulative inorganic phosphorus released from Method 1314 was $<1 \%$ of the quantity released in soluble $313(\mathrm{H} 1)$ pool for both sludge and ash, even when differences in L/S ratios between methods were considered. 
314 This lack of alignment is problematic. Readily soluble phosphorus is the primary concern for receiving

315 waters (5). Overestimation of this pool could result in insufficient phosphorus being applied to crops

316 whereas underestimation risks contributing to eutrophication. The discrepancy between the LEAF and

317 Hedley results for readily soluble phosphorus is probably caused by the Hedley's use of anion exchange

318 resin, which likely extracts low-leachability phosphorus bound to solids $(51,52)$.

319 Hedley is also inconsistent with Method 1313 for the labile (H2), loosely bound (H3), and moderately 320 bound $(\mathrm{H} 4)$ phosphorus pools (Figure 3$)$, whereas non-labile $(\mathrm{H} 5)$ and residual $(\mathrm{H} 6)$ pools were in line with

321 Method 1313 results; however, pH values in Hedley are outside the range of Method 1313 (Figure 1c).

322 For sludge, the quantities of labile $(\mathrm{H} 2)$ and loosely bound $(\mathrm{H} 3)$ phosphorus are consistently lower than

323 available phosphorus from corresponding Method 1313 points, opposite to the case for readily soluble

$324(\mathrm{H} 1)$ phosphorus (Figure 3). The resin used in soluble $(\mathrm{H} 1)$ pool may have extracted some phosphorus that

325 would otherwise appear in these subsequent pools, as was observed by (19). For ash, an order of

326 magnitude more phosphorus is released in Hedley labile $(\mathrm{H} 2)$ fraction than by Method 1313 at the same

$327 \mathrm{pH}$. The phosphorus concentrated in ash following thermal treatment of sludge may have exceeded the

328 capacity of the resin used in soluble (H1), enabling release into subsequent pools. Consistent with sludge,

329 phosphorus concentrations in Hedley loosely bound (H3) and moderately bound (H4) pools in ash are

330 lower than corresponding points in Method 1313. The large portion of sorbed phosphorus removed within

331 labile $(\mathrm{H} 2)$ pool may have caused only more strongly bound phosphorus to remain, reducing the

332 proportion of phosphorus extracted within the loosely bound $(\mathrm{H} 3)$ pool. These discrepancies demonstrate

333 an important drawback to Hedley and other sequential fractionation procedures: pools quantified in each

334 extraction step influence pools quantified in subsequent steps $(19,44)$. Incorporating mineralogy into 335 phosphorus analyses has the potential to improve our interpretation and understanding of these results

$336(27,31)$. Phosphorus mineralogy of virgin sewage sludge is challenging $(53)$ and research in this area is 337 limited. Minerals such as hydroxyapatite, brushite, monetite, and others have been identified in sludges 
338 (53,54). Mineral phases seem to depend on source materials; wastewater treatment processes and operating conditions; and subsequent sludge handling processes. For examples, phosphorus mineral

340 transformations have been observed after low temperature drying processes (53). High temperature

341 treatment likely causes further transformations $(27,31)$. This work provides important groundwork for

342 future research exploring phosphorus mineralogy of sewage sludge and transformations brought about 343 by thermal treatment.

\section{Conclusions}

345 Hedley and LEAF methods provide trends in available phosphorus that are qualitatively consistent. In this 346 study, both suggest that thermal treatment of the sludge changes phosphorus minerals into forms that 347 are more strongly bound to the solid surfaces. Therefore, phosphorus is less likely to leach from the ash 348 in the short term, providing a more regulated source of gradual inorganic phosphorus with less potential 349 harm to downstream water bodies.

350 However, Hedley and LEAF methods provide quantitative differences and LEAF is concluded to be superior

351 for the following reasons. First, more incomplete phosphorus extraction from sludge than ash using 352 Hedley suggests that it may be less appropriate for organic materials; this is consistent with previous 353 studies and limits its applicability. Second, Hedley phosphorus pools were mostly at extreme pH 354 conditions while LEAF (Method 1313) provided results across a range of controlled pH conditions relevant 355 to land application. Third, Hedley overpredicted readily available phosphorus and underpredicted less 356 soluble forms. Moreover, Hedley overpredicted the amount that would rapidly leach as inferred by LEAF 357 (Method 1313) and directly quantified in LEAF (Method 1314). LEAF avoids the problem of sequential 358 fractionation procedures where pools quantified in each extraction step influence pools quantified in 359 subsequent steps. Fourth, LEAF was found to be practically simpler to execute and, while requiring more 360 sample, the results may be more representative. Fifth, LEAF additionally provides analysis of PTEs, which 
361 are valuable for decision-making. In this study, smaller initial releases, lower availability in

362 environmentally relevant conditions, and lower total contents in ash are promising indicators that land

363 application of ash would likely result in less PTE release to soil compared to land application of sludge.

364 Although these elements could be analyzed in the Hedley extracts, that method was not designed for such

365 purposes.

366 This analysis shows the value of the USEPA LEAF Methods in understanding phosphorus availability from

367 materials such as sewage sludge before and after treatment. Land application of a material will change

368 soil pH, which influences phosphorus availability and leaching of PTEs. LEAF was shown to provide valuable

369 and superior insights into the effects of fluctuations in $\mathrm{pH}$, dynamic leaching, and availability of PTEs. This

370 information is essential for assessing material reuse and land application options. It is expected that LEAF

371 will be similarly beneficial, relative to sequential fractionation methods (e.g., Hedley), when applied to

372 soils and other relevant matrices.

\section{Acknowledgements}

374 Funding was provided by the Ontario Ministry of Research, Innovation and Science; the Government of

375 Canada through the Federal Economic Development Agency for Southern Ontario through the Ontario

376 Water Consortium's Advancing Water Technologies Program with in-kind support from Savron Ltd. It was

377 also supported by the Natural Sciences and Engineering Research Council of Canada and the Government

378 of Ontario. We also acknowledge the assistance of summer student, Kia Barrow, with laboratory

379 experiments and analyses.

\section{Supplementary Materials}

381 Supplementary data associated with this article can be found, in the online version, at: 


\section{References}

383 1. Maguire RO, Sims JT. Soil Testing to Predict Phosphorus Leaching. J Environ Qual.

$384 \quad 2002 ; 31(5): 1601-9$.

385 2. Abdala DB, da Silva IR, Vergütz L, Sparks DL. Long-term manure application effects on phosphorus 386 speciation, kinetics and distribution in highly weathered agricultural soils. Chemosphere.

387 2015;119:504-14.

3. Jalali M, Ostovarzadeh $\mathrm{H}$. Evaluation of phosphorus leaching from contaminated calcareous soils due to the application of sheep manure and ethylenediamine tetraacetic acid. Environ Earth Sci. $2009 ; 59(2): 441-8$.

391

4. Turner BL, Haygarth PM. Phosphorus Forms and Concentrations in Leachate under Four Grassland Soil Types. Soil Sci Soc Am J. 2000;64(3):1090-9.

5. Johnston A, Steen I. Understanding phosphorus and its use in agriculture. Brussels: European Fertilizer Manufacturers Association; 2002.

6. Gerdes P, Kunst S. Bioavailability of phosphorus as a tool for efficient P reduction schemes. In: Water Science and Technology. Elsevier Sci Ltd; 1998. p. 241-7.

397 7. Hedley MJ, Stewart JWB, Chauhan BS. Changes in Inorganic and Organic Soil Phosphorus $398 \quad$ Fractions Induced by Cultivation Practices and by Laboratory Incubations. Soil Sci Soc Am J. $1982 ; 46(5): 970-6$.

8. Chen M, Ma LQ. Taxonomic and Geographic Distribution of Total Phosphorus in Florida Surface Soils. Soil Sci Soc Am J. 2001;65(5):1539-47.

402 9. Cross AF, Schlesinger WH. A literature review and evaluation of the. Hedley fractionation: 
Applications to the biogeochemical cycle of soil phosphorus in natural ecosystems. Geoderma. 1995;64(3-4):197-214.

10. Condron LM, Frossard E, Tiessen H, Newmans RH, Stewart JWB. Chemical nature of organic phosphorus in cultivated and uncultivated soils under different environmental conditions. J Soil Sci. 1990;41(1):41-50.

11. Linquist BA, Singleton PW, Cassman KG. Inorganic and organic phosphorus dynamics during a build-up and decline of available phosphorus in an ultisol. Soil Sci. 1997;162(4):254-64.

12. Pansu M, Gautheyrou J. Handbook of soil analysis: mineralogical, organic and inorganic methods. Springer Science \& Business Media; 2007.

13. Tiessen $\mathrm{H}$, Moir J. Characterization of available $\mathrm{P}$ by sequential extraction. In: Soil sampling and methods of analysis. 7th ed. 1993. p. 5-229.

14. Zhang H, Kovar J. Fractionation of soil phosphorus. In: Methods of phosphorus analysis for soils, sediments, residuals, and waters. 2 nd ed. 2009. p. 50-60.

15. Huang X-L, Chen Y, Shenker M. Chemical Fractionation of Phosphorus in Stabilized Biosolids. J Environ Qual. 2008;37(5):1949-58.

16. Iyamuremye F, Dick RP, Baham J. Organic amendments and phosphorus dynamics: Il. distribution of soil phosphorus fractions. Soil Sci. 1996;161(7):436-43.

17. Bolan NS, Hedley MJ. Dissolution of phosphate rocks in soils. 2. Effect of pH on the dissolution and plant availability of phosphate rock in soil with pH dependent charge. Fertil Res. 1990;24(3):125-34.

18. Neyroud J-A, Lischer P. Do different methods used to estimate soil phosphorus availability across 
Europe give comparable results? J Plant Nutr Soil Sci. 2003;166(4):422-31.

425 19. Soinne H. Extraction methods in soil phophorus characterisation- Limitations and applications.

$426 \quad$ University of Helsinki, Helsinki, Finland; 2009.

427 20. Cade-Menun BJ, Preston CM. A comparison of soil extraction procedures for 31P NMR spectroscopy. Soil Sci. 1996;161(11):770-85.

21. Gikonyo EW, Zaharah AR, Hanafi MM, Anuar AR. Degree of phosphorus saturation and soil phosphorus thresholds in an ultisol amended with triple superphosphate and phosphate rocks. ScientificWorldJournal. 2011;11:1421-41.

22. Guggenberger G, Christensen BT, Rubaek G, Zech W. Land-use and fertilization effects on P forms in two European soils: resin extraction and 31P-NMR analysis. Eur J Soil Sci. 1996;47(4):605-14.

434 23. Hartikainen H, Yli-Halla M. Solubility of soil phosphorus as influenced by urea. Zeitschrift für 435 Pflanzenernährung und Bodenkd. 1996;159(4):327-32.

24. Hartmann T, Wollmann I, You Y, Müller T. Sensitivity of Three Phosphate Extraction Methods to the Application of Phosphate Species Differing in Immediate Plant Availability. Agronomy. 2019;9(1):29.

25. Johnson AH, Frizano J, Vann DR. Review: Biogeochemical implications of labile phosphorus in forest soils determined by the Hedley fractionation procedure. Oecologia. 2003;135:487-99.

441 26. González Medeiros JJ, Pérez Cid B, Fernández Gómez E. Analytical phosphorus fractionation in sewage sludge and sediment samples. Anal Bioanal Chem. 2005;381(4):873-8.

443 27. Qian TT, Jiang H. Migration of phosphorus in sewage sludge during different thermal treatment 444 processes. ACS Sustain Chem Eng. 2014;2(6):1411-9. 
28. Self-Davis M, Moore Jr P. Determining water-soluble phosphorus in animal manure. In: Soil sampling and methods of analysis. Raleigh, NC; 2000. p. 74-6.

29. Xu H, Zhang H, Shao L, He P. Fraction distributions of phosphorus in sewage sludge and sludge ash. Waste and Biomass Valorization. 2012;3(3):355-61.

30. $\mathrm{Xu} \mathrm{H}, \mathrm{He} \mathrm{P}, \mathrm{Gu} \mathrm{W}$, Wang G, Shao L. Recovery of phosphorus as struvite from sewage sludge ash. J Environ Sci (China). 2012 Aug 1;24(8):1533-8.

31. Han X, Wang F, Zhou B, Chen H, Yuan R, Liu S, et al. Phosphorus complexation of sewage sludge during thermal hydrolysis with different reaction temperature and reaction time by P K-edge XANES and 31P NMR. Sci Total Environ. 2019 Oct 20;688:1-9.

32. Kosson DS, Garrabrants A, Thorneloe S, Fagnant D, Helms G, Connolly K, et al. Leaching Environmental Assessment Framework (LEAF) How-To Guide: Understanding the LEAF Approach and How and When to Use It. Nashville, TN; 2017.

33. USEPA. Method 1313: Liquid-Solid Partitioning as a Function of pH for Constituents in Solid Materials Using a Parallel Batch Extraction Procedure. Nashville, TN; 2012.

34. USEPA. Method 1314: Liquid-Solid Partitioning as a Function of Liquid-to-Solid Ratio for Constituents in Solid Materials Using a Percolation Column Procedure. Nashville, TN; 2012.

35. Tiwari MK, Bajpai S, Dewangan UK, Tamrakar RK. Suitability of leaching test methods for fly ash and slag: A review. J Radiat Res Appl Sci. 2015;8(4):523-37.

36. Zhang Y, Chen J, Likos WJ, Edil TB. Leaching Characteristics of Trace Elements from Municipal Solid Waste Incineration Fly Ash. In: Geo-Chicago 2016. Reston, VA: American Society of Civil Engineers; 2016. p. 168-78. 
37. Kosson DS, Garrabrants AC, DeLapp R, van der Sloot HA. PH-dependent leaching of constituents of potential concern from concrete materials containing coal combustion fly ash. Chemosphere. 2014;103:140-7.

38. Fang W, Wei Y, Liu J. Comparative characterization of sewage sludge compost and soil: Heavy metal leaching characteristics. J Hazard Mater. 2016;310:1-10.

39. Jiang $L G$, Liang $B, X u e ~ Q$, Yin CW. Characterization of phosphorus leaching from phosphate waste rock in the Xiangxi River watershed, Three Gorges Reservoir, China. Chemosphere. 2016;150:130-8.

40. Jiang L, Yin C, Liang B. Effects of environmental $\mathrm{pH}$ on phosphorus leaching characteristics of phosphate waste rock deposited within Xiangxi River watershed. Chinese J Environ Eng. 2016;10(5):2674-80.

41. Telliard W. Method 1684: Total, fixed, and volatile solids in water, solids, and biosolids. Washington; 2001.

42. Element C. SW-846 Method 3051A: Microwave Assisted Acid Digestion of Sediments, Sludges, Soils, and Oils. 2007.

43. Hedley MJ, Stewart JWB. Method to measure microbial phosphate in soils. Soil Biol Biochem. 1982;14(4):377-85.

44. Turner BL, Cade-Menun BJ, Condron LM, Newman S. Extraction of soil organic phosphorus. Talanta. 2005;66(2 SPEC. ISS.):294-306. 
487 46. Ivanov K, Zaprjanova P, Petkova M, Stefanova V, Kmetov V, Georgieva D, et al. Comparison of inductively coupled plasma mass spectrometry and colorimetric determination of total and extractable phosphorus in soils. In: Spectrochimica Acta - Part B Atomic Spectroscopy. Elsevier; 2012. p. 117-22.

47. Pfaff JD. METHOD 300.0 DETERMINATION OF INORGANIC ANIONS BY ION CHROMATOGRAPHY ENVIRONMENTAL MONITORING SYSTEMS LABORATORY OFFICE OF RESEARCH AND

DEVELOPMENT U.S. ENVIRONMENTAL PROTECTION AGENCY CINCINNATI, OHIO 45268. 1993.

48. Lehmann J, Kleber M. The contentious nature of soil organic matter. Vol. 528, Nature. Nature Publishing Group; 2015. p. 60-8.

49. Ulery AL, Graham RC. Forest Fire Effects on Soil Color and Texture. Soil Sci Soc Am J. 1993;57(1):135-40.

50. Thygesen AM, Wernberg O, Skou E, Sommer SG. Effect of incineration temperature on phosphorus availability in bio-ash from manure. Environ Technol. 2011;32(6):633-8.

51. Koopmans GF, Chardon WJ, McDowell RW. Phosphorus Movement and Speciation in a Sandy Soil Profile after Long-Term Animal Manure Applications. J Environ Qual. 2007;36(1):305-15.

52. Schoumans OF, Groenendijk P. Modeling Soil Phosphorus Levels and Phosphorus Leaching from 503 Agricultural Land in the Netherlands. J Environ Qual. 2000;29(1):111-6.

53. Smith SR, Triner NG, Knight JJ. Phosphorus Release and Fertiliser Value of Enhanced-Treated and 505 Nutrient-Removal Biosolids. Water Environ J [Internet]. 2002 May 1 [cited 2021 Feb 15];16(2):127-34. Available from: http://doi.wiley.com/10.1111/j.1747-6593.2002.tb00383.x

507 54. Frossard E, Tekely P, Grimal JY. Characterization of phosphate species in urban sewage sludges by 
